\title{
Brazing Development and Interfacial Metallurgy Study of Tungsten and Copper Joints with Eutectic Gold Copper Brazing Alloy
}

\author{
David Easton $^{\mathrm{a}}$, Yuxuan Zhang ${ }^{\mathrm{a}}$, James Wood ${ }^{\mathrm{a}}$, Alexander Galloway ${ }^{\mathrm{a}}$, Mikael Olsson Robbie ${ }^{\mathrm{a}}$, \\ Christopher Hardie \\ ${ }^{a}$ University of Strathclyde, Department of Mechanical Engineering, Glasgow, G1 $1 X J$ \\ ${ }^{b}$ Culham Centre for Fusion Energy CCFE, Culham Science Centre, Oxfordshire, OX14 3DB, UK
}

Current proposals for the divertor component of a thermonuclear fusion reactor include tungsten and copper as potentially suitable materials. This paper presents the procedures developed for the successful brazing of tungsten to oxygen free high conductivity (OFHC) copper using a fusion appropriate gold based brazing alloy, Orobraze 890 (Au80Cu20). The objectives were to develop preparation techniques and brazing procedures in order to produce a repeatable, defect free butt joint for tungsten to copper. Multiple brazing methods were utilised and brazing parameters altered to achieve the best joint possible. Successful and unsuccessful brazed specimens were sectioned and analysed using optical and scanning electron microscopy, EDX analysis and ultrasonic evaluation. It has been determined that brazing with Au80Cu20 has the potential to be a suitable joining method for a tungsten to copper joint.

Keywords: dissimilar, material, brazing, tungsten, copper, characterisation

\section{Introduction}

The divertor of a demonstration thermonuclear fusion reactor (e.g. DEMO) will be subjected to unprecedented high thermal loads of up to $10-20 \mathrm{MW} / \mathrm{m}^{2}$ and high neutron fluxes $[1,2]$. Tungsten has been proposed as a potentially suitable armour material due to a beneficially high melting point, high thermal conductivity and high yield and shear stress [3-5]. However undesirable characteristics of tungsten include high brittleness, high hardness and a high ductile to brittle transition temperature (DBTT). This makes tungsten unsuitable as a structural material if operating below the transition temperature[1]. It has therefore been proposed to join the tungsten armour tile with a material suitable for use as a structural and heat sinking component [6,7]. Copper alloys have been identified as a solution due to its high thermal conductivity amongst other properties $[7,8]$. High temperature brazing is a joining method that could be used to join the tungsten armour tile with the copper structure $[1,3,9]$. The inherently high stresses in the divertor, coupled with high discontinuity stresses caused by large differences in thermal and mechanical properties of tungsten and copper, require a strong and repeatable joint between the two materials. For the work presented here, a eutectic gold and copper (Au80Cu20) brazing alloy was selected to join the dissimilar materials due to the low neutron activation of gold and the readiness of $\mathrm{Au} 80 \mathrm{Cu} 20$ to wet with refractory metals[10][11].

\section{Experimental Procedures}

\subsection{Braze Batches}

A number of specimens were fabricated using different brazing processes. Table 1 shows all of the brazing batches that were performed.
All of the vacuum furnace brazing was performed commercially. For the purposes of comparison two different companies were used, with brazing conditions kept as similar as possible. Induction brazing, also under vacuum, was performed in-house by the authors. The brazing set up for the vacuum furnace brazing $A$ and induction brazing methods can be seen in Fig $1 \mathrm{a}$ and $1 \mathrm{~b}$ respectively.

Table 1. Braze batch matrix

\begin{tabular}{|c|c|c|c|c|c|}
\hline Batch & Braze Method & Brazing Alloy & $\begin{array}{c}\text { Tungsten } \\
\text { Type }\end{array}$ & Copper Type & Braze Temp $\left({ }^{\circ} \mathrm{C}\right)$ \\
\hline A & Vacuum $\mathrm{A}$ & Au80Cu19Fe1 & A & OFHC & 1000 \\
\hline$B$ & Vacuum $A$ & Au80Cu20 & A & CW004A & 930 \\
\hline C & Vacuum A & Au80Cu20 & A & CW004A & 950 \\
\hline$D$ & Vacuum A & Au80Cu20 & $B$ & OFHC & 950 \\
\hline$E$ & Vacuum B & Au80Cu20 & A & CW004A & 950 \\
\hline $\mathrm{F}$ & Induction & Au80Cu20 & $B$ & OFHC & 950 \\
\hline$G$ & Induction & Au80Cu20 & A & OFHC & 950 \\
\hline $\mathrm{H}$ & Induction & Au80Cu20 & $A$ & CW004A & 950 \\
\hline
\end{tabular}

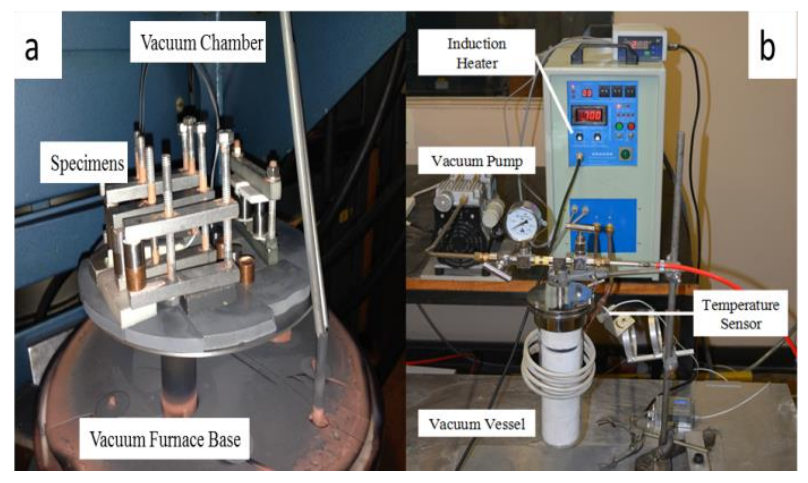

Fig. 1 Brazing set up (a) Vacuum furnace brazing and (b) Induction brazing with vacuum 
Every specimen consists of one $12.7 \mathrm{~mm}$ diameter $10 \mathrm{~mm}$ long billet of tungsten, one of copper, and a $0.05 \mathrm{~mm}$ thick layer of brazing alloy. A specimen that is representative of each batch has been selected and presented here for the purposes of discussion and comparison. Specimen A1 is a specimen from batch A.

\subsection{Materials and Surface Preparation}

The brazing alloy used is eutectic gold copper filler. The Au80Cu19Fe1 "Orobraze 910" and Au80Cu20 "Orobraze 890" are both commercially available and were procured from Johnson Matthey [12]. The brazing alloy was supplied in foil form with a thickness of 50 microns $(0.05 \mathrm{~mm} / 0.002 \mathrm{inch})$. The foils were cut to a size slightly smaller than the diameter of the parent materials, $12.7 \mathrm{~mm}$. The melting point of the alloy is about $910^{\circ} \mathrm{C}$ and can be seen in the alloy phase diagram [13]. The brazing temperature, $\mathrm{T}_{\text {braze, }}$ seen in Table 1 varies from $930-1000^{\circ} \mathrm{C}$ which is sufficiently above the melting temperature of the brazing alloy.

The parent materials comprise of high purity tungsten and copper. Both source A and B of the tungsten are commercially available pure tungsten. The tungsten was supplied in $12.7 \mathrm{~mm}$ (1/2 inch) rod.. Tungsten type A was supplied having been cut to size using electron discharge machining (EDM) and tungsten source 2 had been cut to size using a turning method on a lathe. Further attempts by the authors to machine tungsten were problematic due to the high hardness of tungsten. Water jet cutting and EDM were utilised, although achieving a dimensionally tolerant cut was not always achieved. There was not found to be any significant differences between the two sources of tungsten.
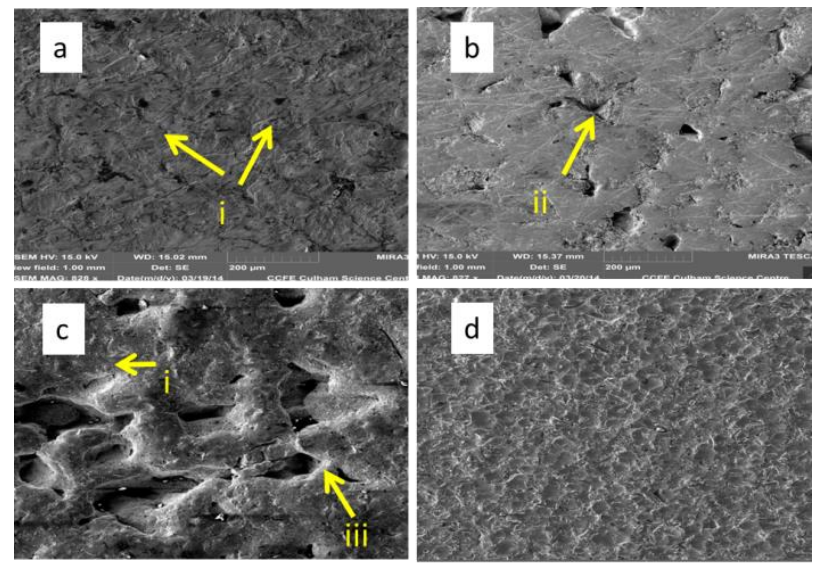

Fig. 2 SEM images at 830 magnification of (a) W wire cut (b) W 800 grit hand ground (c) W grit blasting and (d) $\mathrm{Cu}$ grit blast

Both types of copper used are commercially available and high in purity. CW004a copper is of $99.9 \%$ purity supplied by Aalco [14]. The OFHC copper is of $99.99 \%$ purity and supplied by Durbin Metals [15].

One objective of this work was to determine the optimal surface roughness of the parent materials to achieve the best joint possible. It is known that a highly polished surface can produce a good quality joint. However, some texturing on the surface in the form of fine channels can aid the capillary action of the brazing process, resulting in a larger wetted area. The increased surface contact area can also increase the amount of diffusion between parent materials and braze alloy [14]. The additional wetting could reduce the amount of voids in the joint as a larger proportion of the surface is covered. In brazing batch B (see Table 1) the tungsten and copper were each prepared with 3 different surface conditions for brazing. Fig 2 a shows an SEM image at 830 magnification of the surface of the tungsten as cut using EDM, Fig 2b shows tungsten that's ground with 800 grit size paper and Fig 2c shows tungsten that was grit blasted using white fused alumina (F 230 grade) particles. Fig $2 \mathrm{~d}$ is copper that was grit blasted. It can be seen that microcracks are present in the tungsten, shown at (i) in Fig 2a,b,c. The grinding causes large removal of material seen at (ii) in Fig $2 b$. These imperfections are accentuated using the more aggressive grit blasting as seen at (iii) in Fig 2c where the removed material is the size of entire grains. This can be expected due to the brittleness of the material. This is contrast by the copper in Fig $2 d$ which remains much smoother and largely defect free for all preparation methods. These defects should be considered when designing the brazed joint as a higher extent of cracking/imperfections could lead to degraded fatigue life if present near the materials edge or in a high stress area.

\subsection{Vacuum Furnace Brazing}

Two methods of brazing were considered for producing the $\mathrm{W}-\mathrm{AuCu}-\mathrm{Cu}$ joint. The first was high temperature vacuum furnace brazing. Both vacuum furnace brazes that were performed were kept as similar as possible to allow for accurate comparison. The furnace set up for vacuum braze is seen in Fig 1a. All of the materials were cleaned thoroughly using firstly an ultrasonic alcohol bath, followed by a final cleaning with acetone. The samples were clamped together to minimise misalignment. The samples were then place in the vacuum chamber. A vacuum of $1 \times 10^{-4}$ to $1 \times 10^{-5}$ millibar was drawn. The furnace was heated to the appropriate $\mathrm{T}_{\text {braze }}$ at a rate of about $10^{\circ} \mathrm{C} / \mathrm{min}$. The furnace dwelled at $\mathrm{T}_{\text {braze }}$ for 5 minutes before slowly cooling over several hours to avoid thermal shock.

\subsection{Induction Brazing}

Induction brazing was performed at the University of Strathclyde seen in Fig 1b. An induction heating machine with output power up to $25 \mathrm{KW}$ and working frequency between $30-80 \mathrm{KHz}$ was used to perform the brazing. An infrared temperature sensor with a range of $200-1500^{\circ} \mathrm{C}$ was used for temperature control. Materials were cleaned with acetone. The samples were clamped and then placed into the vacuum vessel. The vacuum was drawn to $1 \times 10^{2}$ millibar. The induction machine heated the vessel to $950^{\circ} \mathrm{C}$ in 110 seconds and dwelled for 2 minutes. The vessel was then left to cool down until below $200^{\circ} \mathrm{C}$, the cooling generally took around 100 minutes. The vacuum was retained through the whole process.

\subsection{Analysis Techniques}


Following the brazing process, samples were prepared using standard metallurgical techniques of sectioning, mounting, grinding and polishing. Optical microscopy and SEM analysis were performed, as well as EDX for certain samples. Joint quality was assessed by inspecting the sectioned joints optically.

Non-destructive evaluation (NDE) was trialled as a method of assessing joint quality. A scanning acoustical microscope (SAM) was used to inspect a number of the brazed specimens. Although there were some potentially useful images, the technique of using the SAM to inspect a region so thin compared to the thickness of the specimen has to be developed further to yield reliable results.

\section{Results and Discussion}

\subsection{Vacuum Furnace Brazing}

The analysis on the specimens from brazing batch A has previously been published by the authors [16]. It was found that a W-Au80-Cu19Fe1-Cu dissimilar material joint can be achieved. The joint displayed negligible elemental transition at the tungsten interface and a gentle transition due to diffusion at the copper interface. However it was recognised that a lack of wetting was a problem. Some samples showed visible lack of wetting upon visual inspection. Fig $3 \mathrm{a}$ and $3 \mathrm{~b}$ shows samples A1 and A2 respectively, which exhibited areas of good bonding but also large voids. Due to the high thermal stresses in the divertor, it is desirable to maintain as fully bonded a surface as possible, as voids could degrade heat transfer capability [11]. Future brazing batches used a different gold-copper brazing alloy to attempt to rectify this issue.

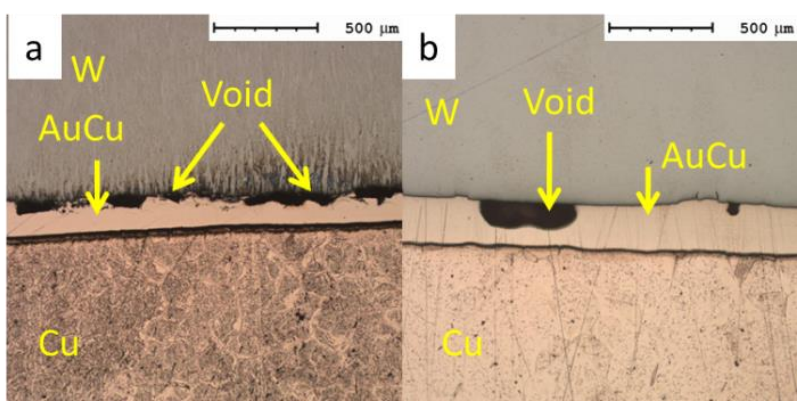

Fig. 3 Optical microscope image at 50x magnification of (a) Specimen A1 and (b) A2 exhibiting voids

Brazing batches $\mathrm{B}$ and $\mathrm{C}$ used the newer $\mathrm{Au} 80 \mathrm{Cu} 20$ brazing alloy. Batch $\mathrm{B}$ was performed at $930^{\circ} \mathrm{C}$. The specimens completely failed to bond. Fig $4 \mathrm{a}$ and $4 \mathrm{~b}$ show specimens $\mathrm{B} 1$ and $\mathrm{C} 1$ respectively.

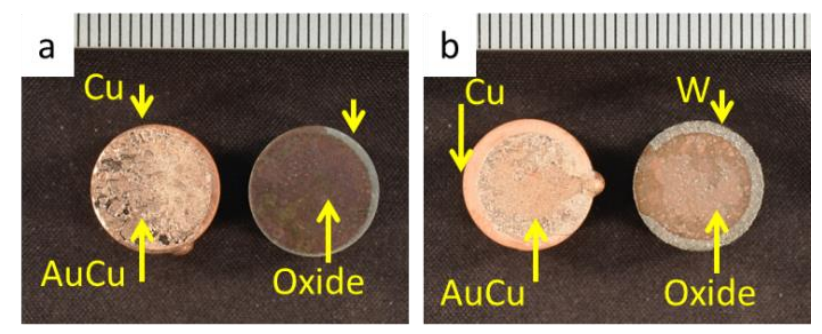

Fig.4 (a) Specimen B1 and (b) Specimen C1
Following the failed attempt at bonding in batch B, low $\mathrm{T}_{\text {braze }}$ or specimen/chamber contamination were identified. An increase in $\mathrm{T}_{\text {braze }}$ and careful cleaning for batch $\mathrm{C}$ still resulted in failure. It is highly likely that the cause of the failed braze is the grade of copper used. The OFHC copper used in batch A is of higher purity than the CW004a in batches B and C (see section 2.2). The extra oxygen in the CW004a is being released during the brazing process, forming an oxide layer that acts as a barrier to bonding. This oxide layer can be seen in Fig. 4 .

Braze batch $E$ was a repetition of batch C's parameters performed at a different facility, vacuum furnace $\mathrm{B}$ in Table 1 . The outcome was identical to batches $\mathrm{B}$ and $\mathrm{C}$. There was no bonding and a visible oxide layer.

A further braze run was performed under the same conditions as batch $\mathrm{C}$, although the copper was changed to the OFHC grade. Braze batch D resulted in successful brazing of tungsten and copper with the $\mathrm{Au} 80 \mathrm{Cu} 20$ alloy as can be seen in Fig. 5 .

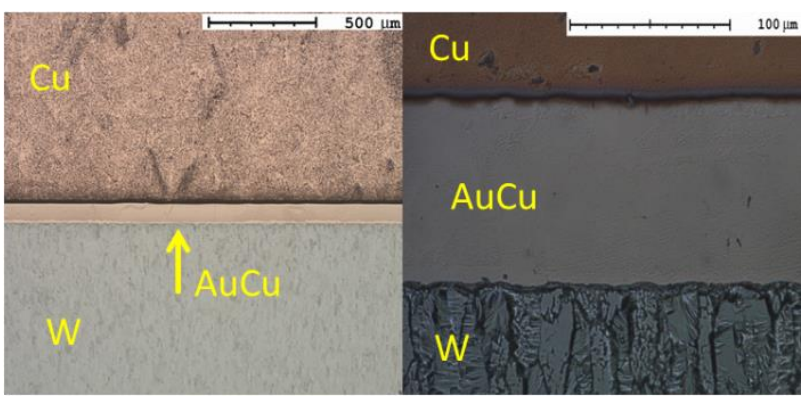

Fig. 5 (a) Specimen D1 50x and (b) Specimen D1 500x

Fig. 5a shows the center area of specimen D1 at 50x magnification, with Fig. $5 \mathrm{~b}$ showing the same area under $500 \mathrm{x}$ magnification. It can be seen that the joint is seemingly flaw free and $100 \%$ wetted. This is a marked improvement from batches $\mathrm{B}$ and $\mathrm{C}$ which resulted in no braze at all. Batch $\mathrm{D}$ also represents an improvement on batch $\mathrm{A}$, the difference between the batches being the newer brazing alloy. The elimination of voids in specimen D1 is a promising sign that the Au80Cu20 braze alloy could be suitable for fabricating $\mathrm{W}-\mathrm{Cu}$ mechanical testing specimens.

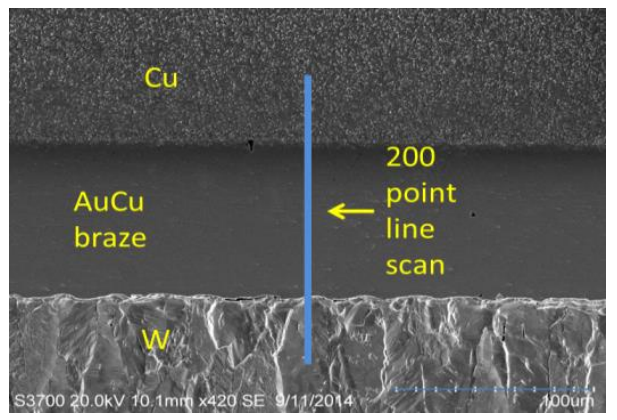

Fig. 6 Specimen D1 SEM image of EDX line scan area

The elemental characteristics of the interface of specimen D1 were examined using SEM and EDX analysis. Fig. 6 shows an SEM image of specimen D1. A line scan was performed over the braze alloy and both interfaces. The line measured about 170 microns, with 
200 points selected on the line to accurately capture the elemental composition. The results of the scan can be seen in Fig. 7 which shows that there is a diffusion zone along the $\mathrm{Cu}-\mathrm{AuCu}$ interface. At the $\mathrm{W}-\mathrm{AuCu}$ interface there is a very sharp transition with almost no diffusion. This is to be expected due to the higher diffusivity between copper and gold than of copper/gold to tungsten. There are no solid solutions of tungsten in the braze region and as with batch $\mathrm{A}$ there are no intermetallic compounds forming.

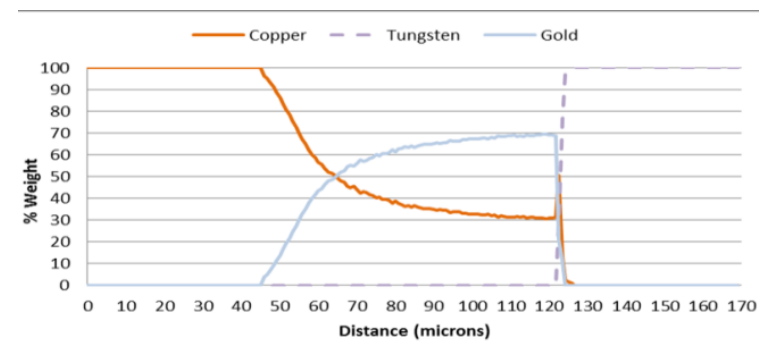

Fig 7. Specimen D1 EDX line spectrum

\subsection{Induction Brazing}

The purpose of the final batches of brazing was to further investigate the reasons for success and failure in previous brazes and to develop the induction brazing process. Specimens F1 and G1 used the OFHC copper with tungsten source A and B respectively, and $\mathrm{H} 1$ used the lesser purity CW004a copper.

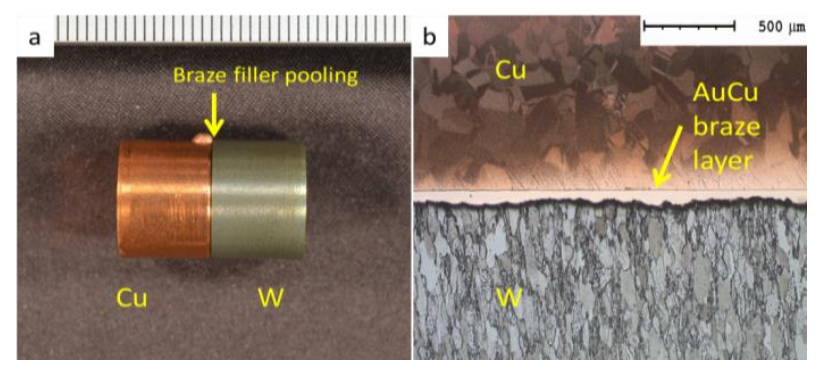

Fig. 8 (a) Specimen G1 and (b) Specimen F1 50x mag

Fig. 8a shows specimen G1 post braze. There is a volume of brazing alloy that has pooled on the outside of the specimen. This is due to capillary action during the brazing process drawing the filler metal to the edge. Consideration would have to be taken should mechanical testing samples be fabricated, particularly fatigue samples, as this collection of brazing alloy could degrade fatigue life by acting as a stress concentrator.

Fig. $8 \mathrm{~b}$ is an optical microscope image of specimen F1. The joint width is not uniform across the length of the joint. There are no visible voids. This suggests that induction brazing under vacuum could be used in addition to vacuum furnace brazing for developing understanding of the brazed joints and their mechanical properties.

The attempted braze using the CW004a copper, batch $\mathrm{H}$, can be seen in Fig. 9. Initially specimen $\mathrm{H} 1$ appeared to have brazed successfully. However, during sectioning the joint failed and the specimen broke along the interface seen in Fig 9b. It can be seen in Fig. 9a that there is a degree of oxidation on the copper around the braze region, visible as the discoloured region (i). This strengthens the proposition that the CW004a grade of copper is unsuitable for the purposes of brazing.

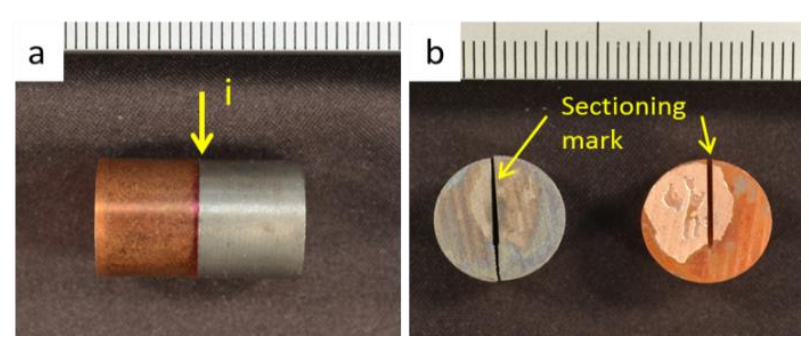

Fig. 9 (a) Specimen $\mathrm{H} 1$ post braze and (b) H1 broken

\section{Conclusions}

- A eutectic gold-copper brazing alloy has been successfully used to produce a highly wetted brazed joint between tungsten and copper in batces $\mathrm{D}, \mathrm{F}$ and $\mathrm{G}$.

- The Au80Cu20 composition results in a high quality braze joint with no/fewer voids than the Au80Cu19Fe1 composition.

- $\mathrm{W}-\mathrm{AuCu}-\mathrm{Cu}$ joints are ready to be applied to tensile test/axial fatigue specimens.

- Care must be taken with the selection of material grade. Whilst OFHC copper is suitable for the application stated here the slightly less pure CW004a is not.

- In-house induction brazing with vacuum offers a low cost, quick turnaround method for developing brazing techniques and understanding of brazed joints.

- Further research into effects of surface roughness on the $\mathrm{W}-\mathrm{AuCu}-\mathrm{Cu}$ joint is required, particularly due to the brittle nature of tungsten.

\section{References}

[1] M. Rieth, et al., J. Nucl. Mater. 432 (2013) 482.

[2] P. Norajitra, S.I. Abdel-Khalik, L.M. Giancarli, T. Ihli, G, Janezshitz, S. Malang, I.V. Mazul, P. Sardain, Fusion Eng. Des. 83 (2008) 893.

[3] P. Norajitra, S. Antusch, R. Giniyatulin, V. Kuznetsov, I. Mazul, H.J. Ritzhaupt-Kleissl, L. Spatafora, Fusion Eng. Des. 86 (2011) 1656.

[4] P. Norajitra, S. Antusch, L. V. Boccaccini, M. Kuzmic, I. Maione, L. Spatafora, Fusion Eng. Des. 87 (2012) 932

[5] http://www.plansee.com.

[6] M. Merola, W. Dänner, M. Pick, Fusion Eng. Des. 75 (2005) 325 .

[7] J. Reiser, M. Rieth, Fusion Eng. Des. 87 (2012) 718.

[8] http://www.kupfer-institut.de.

[9] M. Rieth, et al., J. Nucl. Mater. 417 (2011) 463.

[10] R. Gilbert, Handbook of Activation Data, UKAEA

[11] D. Jacobson, G. Humpston "Priciples of Brazing" ASM Publications

[12] 10 http://www.matthey.com.

[13] 11 Alloy Phase Diagram, ASM Handbook, vol. 3, 1992.

[14] $12 \mathrm{http}: / / \mathrm{www}$. aalco.co.uk.

[15] 13 http://www.durbinmetals.co.uk.

[16] 15 Y, Zhang, A. Galloway, J. Wood, M.B.O. Robbie, D. 
Easton, J. Nucl. Mater. 454 (2014) 207. 